\title{
Cardiac Output and its Components Among Young Athletes During Functional Loads
}

\author{
Vanyushin Yu.S. \\ Physical Upbringing Department, \\ Kazan State Agricultural University \\ Kazan, Russia \\ kaf.fv.kgau@mail.ru
}

\author{
Elistratov D. E., \\ candidate of biological sciences. \\ Physical Upbringing Department, \\ Kazan State Agricultural University \\ Kazan, Russia \\ kaf.fv.kgau@mail.ru
}

Khayrullin R. R.

Physical Upbringing Department,

Kazan State Agricultural University

Kazan, Russia

kaf.fv.kgau@mail.ru

Fedorov N. A., candidate of biological sciences., Kazan State Agricultural University

Kazan, Russia

\begin{abstract}
The aim of the research was in inotropic and chronotropic components revelation, as forming cardiac output, during functional loads among young athletes. 14-16 year-old football players took part in the research (49 people). As a result of the increasing power load there were indices changes of heart pumping ability among football players, which varied depending on the age of the respondents. The used power increasing load at bicycle ergometer can be recommended as a loading test in order to reveal functional and reserve capacities of young football players' heart. It can prove the prevailing influence of inotropic or chronotropic components during cardiac output formation. Functional loads and the age of the respondents influence cardiac output formation in young athletes.
\end{abstract}

Keywords—chronotropic; inotropic; stage-increasing power; bicycle ergometer; cardiac output.

\section{INTRODUCTION}

During teen-age period there is neuroendocrine transformation, which turns it into adolescence. During this age period there is nonconformity between physical, gender and functional development. It especially concerns children and teen-agers, who go in for sport. Their organism goes through additional physical loads and it can influence the functions of the developing organism, changing its environment factors resistance. The base of a person's health is formed during pre-school age. That is why it is reasonable to study the developing organism, when the main physiological systems are formed and it is necessary to know the influence of the definite kinds of sport on a health state of a child's organism. The aim of our research work was in inotropic and chronotropic components revelation, as forming cardiac output, during functional loads among young athletes. Physical Upbringing Department,

kaf.fv.kgau@mail.ru

\section{LITERATURE REVIEW}

Physical exercises and sport are important as they have a great influence on cardiovascular system state, on the activity of which depends physical working capacity and sports results $[1,2,8,9]$. This system is an indicator of the whole organism functioning [3]. In this connection we studied teen-age period, as one of sensitive periods in a child's development, when physical culture lessons form the main factor for a young person's further life. In order to achieve high sports results it is necessary to realize timely and provide the organism with oxygen. One of such kind of mechanisms is blood minute volume increase (cardiac output), which is the result of inotropic and chronotropic effects influence in a form of heart rate (HR) and cardiac stroke volume (CSV) increase. In the opinion of some research workers, inotropic mechanism is more ideal, as in his case HR is decreased and the increase of cardiac output is achieved by means of CSV increase $[4,10]$.

\section{RESEARCH METHODOLOGY}

Young football players at the age of 14-16 took p[art in the experiment (49 people).According to differential rheogram (Kubichek and others, 1974) [5], in modofocation of Yu. S. Vanyushin and other authors (2017), HR, CSV and blood minute volume (BMV) were defined. As functional tests we used active body position change and work at bicycle ergometer of the increasing power without pauses of rest 0.5 , 1.0 and $1.5 \mathrm{~W} / \mathrm{kg}$. Differential rheogram was registered during functional load fulfillment by means of tetrapolar chest rheography. In order to define CSV we used the formula, which had the averaged perimeter of chest $\left(D_{1}+D_{2}\right)^{2} / 4$ for the peculiarities of respondents' body constitution taking into account:

$$
\left.\mathrm{L}\left(\mathrm{D}_{1}+\mathrm{D}_{2}\right)^{2} / 4\right)
$$


$\mathrm{Z}^{2}$

$\mathrm{L}$ - distance between electrodes, $\mathrm{cm}$;

$\mathrm{Z}$ - basic impedance, Ohm;

Ad - amplitude of defferential rheogram, Ohm/s;

$\mathrm{Tu}$ - time of blood expulsion from heart, $\mathrm{s}$.

Blood minute volume (BMV) was calculated as the product of CSV into HR.

\section{RESULTS}

During functional loads fulfillment in all groups of respondents HR increased (table 1,2).

TABLE I. CARDIOVASCULAR SYSTEM INDICES AMONG 14-16 YEAR-OLD ATHLETES DURING BODY POSITION CHANGE

\begin{tabular}{|c|c|c|c|}
\hline \multirow{2}{*}{$\begin{array}{l}\text { Groups of } \\
\text { respondents }\end{array}$} & \multicolumn{3}{|c|}{ Body position } \\
\hline & Lying & Sitting & Standing \\
\hline $\begin{array}{c}14 \text { years-old } \\
\text { (n=13) HR } \\
\text { CSV } \\
\text { BMV }\end{array}$ & $\begin{array}{c}67,06 \pm 3,28 \\
61,14 \pm 1,65 \\
4,07 \pm 0,18\end{array}$ & $\begin{array}{c}76,11 \pm 2,81 \\
41,03 \pm 1,21 \\
3,10 \pm 0,11\end{array}$ & $\begin{array}{c}86,23 \pm 3,91 \\
39,04 \pm 1,57 \\
3,31 \pm 0,11\end{array}$ \\
\hline $\begin{array}{c}15 \text { years-old } \\
(\mathrm{n}=19) \mathrm{HR} \\
\text { CSV } \\
\text { BMV }\end{array}$ & $\begin{array}{c}65,46 \pm 1,94 \\
64,70 \pm 2,06 \\
4,24 \pm 0,20\end{array}$ & $\begin{array}{c}71,68 \pm 2,75 \\
43,33 \pm 1,36 \\
3,07 \pm 0,11\end{array}$ & $\begin{array}{c}78,92 \pm 3,37 \\
40,66 \pm 1,00 \\
3,23 \pm 0,17\end{array}$ \\
\hline $\begin{array}{c}16 \text { years-old } \\
\text { (n=17) HR } \\
\text { CSV } \\
\text { BMV }\end{array}$ & $\begin{array}{c}65,15 \pm 1,98 \\
72,17 \pm 2,23 \\
4,82 \pm 0,24 \\
\end{array}$ & $\begin{array}{c}69,62 \pm 2,01 \\
45,74 \pm 2,02 \\
3,17 \pm 0,16 \\
\end{array}$ & $\begin{array}{c}79,62 \pm 2,53 \\
42,94 \pm 1,74 \\
3,36 \pm 0,18 \\
\end{array}$ \\
\hline
\end{tabular}

HR increase, expressed in percentage, depended on the age of young football players and the kind of functional loads (table. III, IV). The highest HR indices were registered in the group of 14 year-old teen-agers. The reason for this, in our opinion, were initially big values of HR before the load. It means that the initial state of an organism mainly conditions the character of further reactions. It is typical for "the initial value law" [6]. Revealed by us dependence between the reaction of blood circulation to functional loads and the initial state of HR indices contain all features of this law. It shows that the higher the initial activity is, the more distinct is the reaction.

TABLE II. CARDIOVASCULAR SYSTEM INDICES AMONG YOUNG 1416 YEAR OLD ATHLETES DURING PHYSICAL LOAD OF THE INCREASING POWER

\begin{tabular}{|l|c|c|c|}
\hline \multirow{2}{*}{ Load } & \multicolumn{3}{|c|}{ Age } \\
\cline { 2 - 4 } & 14 years-old & 15 years-old & 16 years-old \\
\hline Before the & & & \\
Load & $76,11 \pm 2,81$ & $71,68 \pm 2,75$ & $69,62 \pm 2,01$ \\
HR & $41,03 \pm 1,21$ & $43,33 \pm 1,36$ & $45,74 \pm 2,02$ \\
CSV & $3,10 \pm 0,11$ & $3,07 \pm 0,11$ & $3,17 \pm 0,16$ \\
BMV & & & \\
\hline 0,5 W/kg HR & $103,70 \pm 3,14$ & $94,72 \pm 2,75$ & $88,21 \pm 1,89$ \\
CSV & $39,98 \pm 1,28$ & $40,52 \pm 1,65$ & $39,04 \pm 1,53$ \\
BMV & $4,12 \pm 0,14$ & $3,85 \pm 0,21$ & $3,41 \pm 0,11$ \\
\hline 1,0 W/kg HR & $119,38 \pm 2,49$ & $110,56 \pm 2,61$ & $103,64 \pm 1,79$ \\
CSV & $38,52 \pm 1,65$ & $40,04 \pm 1,27$ & $44,45 \pm 2,11$ \\
BMV & $4,57 \pm 0,17$ & $4,40 \pm 0,14$ & $4,57 \pm 0,19$ \\
\hline 1,5 W/kg HR & $134,54 \pm 2,92$ & $126,56 \pm 2,87$ & $119,05 \pm 1,84$ \\
CSV & $35,35 \pm 1,57$ & $38,37 \pm 1,26$ & $48,95 \pm 2,34$ \\
BMV & $4,69 \pm 0,17$ & $4,86 \pm 0,15$ & $5,79 \pm 0,29$ \\
\hline
\end{tabular}

During the transfer from the lying position to the sitting position and standing position there was CSV values decrease in all groups of respondents. The most considerable changes of this index were during the transfer from lying position to the sitting position and then there were insignificant shifts in CSV values, which is connected with venous blood inflow decrease towards heart with the help of low cava. CSV decrease during the transfer from the lying position into sitting position we mainly saw in the group of 16 year old football players. It was influenced by the volume of low tension circulation widening, which increases with ages [7]. CSV decrease during active body position change is considered as cardiovascular drift [8]. In our research work it is typical for all age groups of young athletes.

TABLE III. INDICES PERCENTAGE OF CARDIAC OUTPUT OF HR AND CSV AMONG YOUNG ATHLETES DURING BODY POSITION CHANGE

\begin{tabular}{|c|c|c|c|c|}
\hline \multirow{2}{*}{$\begin{array}{l}\text { Group of } \\
\text { respondents }\end{array}$} & \multirow[b]{2}{*}{ Indices in $\%$} & \multicolumn{3}{|c|}{ Положение тела } \\
\hline & & Lying & Sitting & Standing \\
\hline 14 years & HR & 52 & 65 & 69 \\
\hline old & CSV & 48 & 35 & 31 \\
\hline 15 years & HR & 50 & 62 & 66 \\
\hline old & CSV & 50 & 38 & 34 \\
\hline 16 years & HR & 47 & 60 & 65 \\
\hline old & CSV & 53 & 40 & 35 \\
\hline
\end{tabular}

BMV decrease in groups in terms of body position change is less expressed, than CSV, which is typical for HR reflex increase. It should be noted that most of all BMV decrease was during the transfer from lying position into sitting position and then there were some shifts of this index. In lying position BMV values, more significant, were registered in the group of 16 year old teen-agers. In the sitting position BMV decreased with the age of teen-agers.

During transfer from one position to another the percentage of HR indices and CSV during cardiac output formation among 14-16 year old athletes changed irrespective of the age (table III). HR contribution into cardiac output formation increased. The volume of CSV decreased. It proves chronotropic component prevalence in the mechanisms of cardiac output formation during position change.

TABLE IV. INDICES PERCENTAGE OF CARDIAC OUTPUT OF HR AND CSV AMONG YOUNG ATHLETES DURING PHYSICAL LOADS OF THE INCREASING POWER

\begin{tabular}{|c|c|c|c|}
\hline \multirow{2}{*}{$\begin{array}{c}\text { Groups of } \\
\text { respondents }\end{array}$} & \multicolumn{3}{|c|}{ Age } \\
\cline { 2 - 4 } $\begin{array}{c}\text { Before the load } \\
\text { HR }\end{array}$ & $65 \%$ & $62 \%$ & 16 years old \\
CSV & $35 \%$ & 38 & $60 \%$ \\
\hline $0,50 \mathrm{~W} / \mathrm{kg}$ & & & $40 \%$ \\
$\mathrm{HR}$ & $72 \%$ & $70 \%$ & $69 \%$ \\
$\mathrm{CSV}$ & $28 \%$ & $30 \%$ & $31 \%$ \\
\hline $1,00 \mathrm{~W} / \mathrm{kg}$ & & & \\
$\mathrm{HR}$ & $76 \%$ & $73 \%$ & $30 \%$ \\
$\mathrm{CSV}$ & $24 \%$ & $27 \%$ & \\
\hline $1,5 \mathrm{~W} / \mathrm{kg}$ & & & $71 \%$ \\
$\mathrm{HR}$ & $79 \%$ & $77 \%$ & $29 \%$ \\
$\mathrm{CSV}$ & $21 \%$ & $23 \%$ & \\
\hline
\end{tabular}


In lying position with the age changes the ratio of $\mathrm{HR}$ and CSV during cardiac output formation. At the age of 14 the prevailing component is chronotropic one, at the age of 15 there is a balance and at the age of 16 inotropic function becomes the leading during cardiac output formation.

In sitting and standing positions with the age HR contribution decreases and CSV value increases.

Thus, the most significant changes of CSV and BMV indices among young football players at the age of 14, 15, 16 happen during the transfer from the lying into sitting position. The most significant HR changes were during the transfer from sitting position into standing position. The revealed physiological regulation is especially important for the reaction determination of young athletes' blood circulation and can be recommended as the testing load of chronotropic or inotropic components in heart activity.

During the load of the increasing power fulfillment at a bicycle ergometer in all groups of respondents power influenced HR, CSV and BMV (Table 2). With its increase HR also increased for a valid volume irrespective of the age. CSV in the groups of 14 and 15 year old football players decreased in terms of the load increase. In the group of 16 year old athletes its decrease was changed for gradual increase. Cardiac output gradually increased irrespective of the age of respondents. However, most of all it happened in the group of 16 year old football players during $1,50 \mathrm{~W} / \mathrm{kg}$ power load fulfillment, which can be connected with CSV increase.

Before the load with age changes HR and CSV ratio during cardiac output formation (table 4).

At the same time HR decreased and CSV increased. However, chronotropic component was prevailing irrespective of age.

During the loads of the following power: $0.5,1.0$ and 1.5 $\mathrm{W} / \mathrm{kg}$ with the age chronotropic component value during cardiac output formation decreased, inotropic function increased.

During the loads of the following power: $0.5,1.0$ и 1.5 $\mathrm{W} / \mathrm{kg}$ during cardiac output formation the value of chronotropic component increased with the load power increase and the role of inotropic function decreased. However, at the age of $16 \mathrm{HR}$ and CSV contribution during cardiac output formation didn't change during the increasing power load.

\section{CONCLUSION}

Thus, the increasing power load led to heart pumping function change in young football players, which changed depending on then respondents' age. The created work of the increasing power can be recommended as a loading test for functional and reserve abilities of heart revelation, which can prove the prevailing influence of chronotropic or inotropic components of a cardiac output.

Summarizing all mentioned above we come to the conclusion that cardiac output formation among young athletes influences functional loads and respondents' age.

\section{References}

[1] Elistratov D.E., Mindubaev A.M. Types of blood circulation influence on physical working capacity of students. Urgent problems of physical culture and sport in terms of modern social-economic conditions: Materials of the International acientific-practical conference, Cheboksary: FSBEE HE Chuvash State Agricultural Academy. 2017, pp. 154-158.

[2] Federov N.A. Studying typological peculiarities of blood circulation influence on pumping function indices among athletes during physical load. Urgent problems of physical culture and sport in modern socialeconomic conditions. Materials of the International scientific-practical conference. FSBEE HE Chuvash State Agricultural Academy. 2016, pp. 239-243.

[3] Vanyushin Yu.S., Khayrullin R.R., Elestratov D.E. The importance of complex estimation coefficient of cardiorespiratory system for athletes' functional state diagnostics, Theory and practice of physical culture. 2017, 5, pp. 59-61.

[4] Abzalov N.I., Abzalov R.A., Nigmatullina R.R. Heart pumping function reserves of a developing organism during hypokinesia and hyperkinesia. Monograph.- Kazan: K(P)FU. 2015, 116.

[5] Kubicek W.G. The Minnesota impedance cardiograph-theory and application. Biomed. Engin. 1974, vol. 9, 9, pp. 410-416.

[6] Petrova V.K., Goilovina E.A.,Shestakova A.A. Heart adaptation among children of senior school age to functional loads. Physical upbringing and student sport as viewed by students. II All-Russian scientific-practical conference with the International participation, dedicated to 85anniversary of Kazan National Research Technical University -Kazan Aviation Institute. 2016, pp. 438-441.

[7] Chinkin A.S., Nazarenko A.S. Physiology of sport. Manual. Moscow. 2016, 120.

[8] Turley K.R. Cardiovascular responses to treadmill and cycle ergometer exercise in children and adults. J. Appl. Physiol. 1997, vol. 83, 3, pp. 948957.

[9] Kolesnikova L.I., Darenskaya M.A., Grebenkina L.A., Sholokhov L.F., Semenova N.V., Dolgikh M..I., Osipova E.V. The peculiarities of compensatory-adaptive reactions of an organism among the female representatives of Evenk ethnos. Journal of evolutional biochemistry and physiology. 2016, vol. 52, 6, pp. 393-397.

[10] Ivanov K.P. Adaptation effectiveness increase and defensive reactions weakening during biological evolution. Journal of evolutional biochemistry and physiology. 2014, vol. 50, 1, pp. 12-18.

[11] Kuznetsova Z.M., Kuznetsov S.A., Ovchinnikov Yu.D., Golovko P.V. Analysis of the morphological-functional indices connection degree in throwing among athletes. 2018, vol. 13(2), pp. 44-51. DOI: 10.14526/02_2018_308.

[12] Alexsandr S. Kuznetsov, Sergei V. Novakovskiy, Oleg B. Solomakhin. About expediency of attack and defense parallel study in Greco-roman wrestling at the stage of initial training. 2018, vol. 13(1), pp. 12-20. DOI: 1-/14526/01_2018_279. 